Case Report

\title{
A Rare Case of Primary Bilateral Adrenal Lymphoma
}

\author{
Veeraraghavan Meyyur Aravamudan, ${ }^{1}$ Phang Kee Fong, ${ }^{1}$ Yang Shiyao Sam, ${ }^{1}$ \\ Pavel Singh, ${ }^{2}$ Siok-Bian $\mathrm{Ng}^{3}$ and Gollamudi Satya Pavan Kumar ${ }^{1}$ \\ ${ }^{1}$ Department of Advanced Internal Medicine, National University Hospital, 5 Lower Kent Ridge Road, Singapore 119074 \\ ${ }^{2}$ Department of Radiology, National University Hospital, 5 Lower Kent Ridge Road, Singapore 119074 \\ ${ }^{3}$ Department of Pathology, National University of Singapore, National University Hospital, 5 Lower Kent Ridge Road, Singapore 119074
}

Correspondence should be addressed to Veeraraghavan Meyyur Aravamudan; veera_meyyur_aravamudan@nuhs.edu.sg

Received 27 February 2017; Revised 26 May 2017; Accepted 6 June 2017; Published 5 July 2017

Academic Editor: Walter Zidek

Copyright (C) 2017 Veeraraghavan Meyyur Aravamudan et al. This is an open access article distributed under the Creative Commons Attribution License, which permits unrestricted use, distribution, and reproduction in any medium, provided the original work is properly cited.

Lymphoma may involve the adrenal glands, but primary lymphoma is rare. Only a few cases have been reported in medical literature. Primary adrenal lymphoma is extremely rare, accounting for $<1 \%$ of non-Hodgkin lymphomas. We here present a case of a middleaged female who presented with persistent fever for three weeks. She also reported significant weight loss of more than $10 \mathrm{kgs}$ over the duration of three months. Computed tomography of the thorax and abdomen and pelvis demonstrated bilateral adrenal masses. She underwent short Synacthen test which showed evidence of adrenal insufficiency. She underwent CT-guided adrenal gland biopsy. Histology of adrenal gland biopsy showed features consistent with diffuse large B-cell lymphoma. She was started on R-CHOP chemotherapy and had a good clinical response and remained in complete remission for five months after chemotherapy.

\section{Introduction}

While the majority of lymphomas arise from lymph nodes, up to a quarter develop from extranodal sites [1]. Amongst these, primary adrenal lymphomas are considerably rare, contributing to $3 \%$ of all non-Hodgkin lymphomas and interestingly in $70 \%$ of the cases both adrenal glands are involved [2]. In this report, we described one such case.

\section{Case Report}

Our patient is a 52-year-old Malay woman who presented with a three-week history of intermittent pyrexia. This was associated with an unintentional weight loss of $10 \mathrm{~kg}$ over three months. She has a past medical history of asthma, hypertension, and hyperlipidaemia.

There were no specific localizing symptoms including cough, sputum, haemoptysis, dysuria, abdominal pain, or diarrhoea. There was also no history of travel.

Parameters revealed pyrexia of 40 degrees Celsius and sinus tachycardia of 113 beats per minutes but normal blood pressure. Physical examination was unremarkable with normal heart and breath sounds. Abdomen was soft, nontender with no palpable masses. There was no cervical, axillary, or inguinal lymphadenopathy. There were no neurological deficits and stigmata of liver disease.

Initial investigations showed microcytic hypochromic anaemia with a haemoglobin of $9.8 \mathrm{~g} / \mathrm{dL}$ and mean cell volume of $75.2 \mathrm{fL}$. Renal function was unremarkable, but there was a raised lactate dehydrogenase (LDH) level of $2140 \mathrm{U} / \mathrm{L}$. Other blood results are summarised in Table 1.

A computed tomography scan of the thorax abdomen and pelvis was performed, and it showed bilateral homogenous adrenal masses measuring $3.7 \times 5.4 \times 6.4 \mathrm{~cm}$ on the left and $5.5 \times 2.7 \times 5.9 \mathrm{~cm}$ on the right (Figures 1 and 2). There was also a prominent left supraclavicular lymph node measuring $0.8 \mathrm{~cm}$ and a few subcentimetre mediastinal lymph nodes measuring up to $0.8 \mathrm{~cm}$.

Early morning cortisol was subsequently found to be low at $242 \mathrm{nmol} / \mathrm{L}$ and short Synacthen test with $250 \mathrm{mcg}$ of tetracosactide did not show adequate cortisol response (Table 1). Acid Fast Bacilli stain and culture alongside with Polymerase Chain Reaction for Tuberculosis (TB PCR) of the patient was negative. 
TABLE 1: Initial blood test results.

\begin{tabular}{|c|c|c|c|}
\hline Test & Results & Unit & $\begin{array}{c}\text { Reference } \\
\text { interval }\end{array}$ \\
\hline White blood cells & 6.45 & $\times 10^{9} / \mathrm{L}$ & $3.40-9.60$ \\
\hline Red blood cells & 3.87 & $\times 10^{12} / \mathrm{L}$ & $3.70-9.60$ \\
\hline Haemoglobin & 9.8 & $\mathrm{~g} / \mathrm{dL}$ & $10.9-15.1$ \\
\hline Mean Cell Volume & 75.2 & $\mathrm{fL}$ & $80.0-95.0$ \\
\hline $\begin{array}{l}\text { Mean corpuscular } \\
\text { haemoglobin }\end{array}$ & 25.3 & pg & $27.0-33.0$ \\
\hline $\begin{array}{l}\text { Mean corpuscular } \\
\text { haemoglobin concentration }\end{array}$ & 33.7 & $\mathrm{~g} / \mathrm{dL}$ & $32.0-36.0$ \\
\hline Haematocrit & 29.1 & $\%$ & $32.7-44.4$ \\
\hline Platelets & 150 & $\times 10^{9} / \mathrm{L}$ & $132-372$ \\
\hline Mean platelet volume & 9.3 & $\mathrm{fL}$ & $8.7-12.2$ \\
\hline Red cell distribution width & 18.2 & $\%$ & $11.4-14.8$ \\
\hline Sodium & 137 & $\mathrm{mmol} / \mathrm{L}$ & $135-145$ \\
\hline Potassium & 4.4 & $\mathrm{mmol} / \mathrm{L}$ & $3.5-5.0$ \\
\hline Chloride & 101 & $\mathrm{mmol} / \mathrm{L}$ & $95-110$ \\
\hline Carbon dioxide & 22 & $\mathrm{mmol} / \mathrm{L}$ & $22-31$ \\
\hline Creatinine & 66 & umol/L & $50-90$ \\
\hline Urea & 4.9 & $\mathrm{mmol} / \mathrm{L}$ & $2.0-6.5$ \\
\hline Glucose & 7.2 & $\mathrm{mmol} / \mathrm{L}$ & $4.0-7.8$ \\
\hline Albumin & 34 & $\mathrm{~g} / \mathrm{L}$ & $38-48$ \\
\hline Bilirubin, total & 7 & umol/L & $5-30$ \\
\hline Bilirubin, conjugated & 1 & umol/L & $0-5$ \\
\hline Aspartate aminotransferase & 64 & $\mathrm{U} / \mathrm{L}$ & $10-50$ \\
\hline Alanine aminotransferase & 48 & $\mathrm{U} / \mathrm{L}$ & $10-70$ \\
\hline Alkaline Phosphatase & 162 & $\mathrm{U} / \mathrm{L}$ & $40-130$ \\
\hline Lactate dehydrogenase & 2140 & $\mathrm{U} / \mathrm{L}$ & $250-580$ \\
\hline Calcium, total & 2.22 & $\mathrm{mmol} / \mathrm{L}$ & $2.15-2.55$ \\
\hline C-reactive protein & 65 & $\mathrm{mg} / \mathrm{L}$ & $0-10$ \\
\hline Iron & 3.3 & umol/L & $8.8-27.0$ \\
\hline Ferritin & 1249 & $\mathrm{ug} / \mathrm{L}$ & $10-120$ \\
\hline Transferrin & 201 & $\mathrm{mg} / \mathrm{dL}$ & $200-360$ \\
\hline Total iron binding capacity & 52 & $\mathrm{umol} / \mathrm{L}$ & $52-94$ \\
\hline Iron saturation & 6 & $\%$ & $15-50$ \\
\hline Thyroxine, free & 12.9 & $\mathrm{pmol} / \mathrm{L}$ & $8.0-20.0$ \\
\hline Thyroid stimulating hormone & 1.59 & $\mathrm{mIU} / \mathrm{L}$ & $0.45-4.5$ \\
\hline Early morning cortisol & 242 & $\mathrm{nmol} / \mathrm{L}$ & $123-623$ \\
\hline $\begin{array}{l}\text { Adrenocorticotropic hormone } \\
\text { (ACTH) }\end{array}$ & 3.1 & $\mathrm{pmol} / \mathrm{L}$ & $0.0-10.2$ \\
\hline \multicolumn{4}{|l|}{ Synacthen test } \\
\hline Cortisol at $0 \mathrm{~min}$ & 150 & $\mathrm{nmol} / \mathrm{L}$ & \\
\hline Cortisol at $30 \mathrm{~min}$ & 191 & $\mathrm{nmol} / \mathrm{L}$ & \\
\hline Cortisol at $60 \mathrm{~min}$ & 209 & $\mathrm{nmol} / \mathrm{L}$ & \\
\hline
\end{tabular}

A left adrenal biopsy was performed, and histology revealed sheets of large lymphoid cells with a prominent intravascular growth pattern. The neoplastic cells were positive for CD20, CD79A, MUM1, BCL6, and BCL2. There was no expression for $\mathrm{CD} 10$, consistent with a nongerminal centre

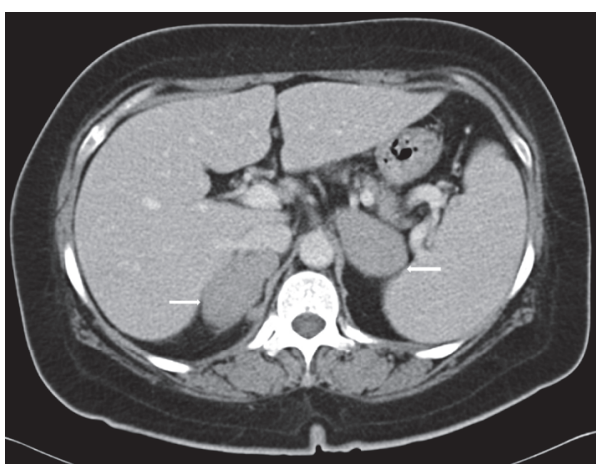

FIgURE 1: At the time of diagnosis. Imaging studies of patient, CT thorax, and abdomen, and pelvis show bilateral adrenal masses which are homogenous measuring $3.7 \times 5.4 \times 6.3 \mathrm{~cm}$ on the left (78.3 average $\mathrm{HU}$ ), while the right adrenal gland measures $5.5 \times 2.7$ $\times 5.9 \mathrm{~cm}(72.7$ average $\mathrm{HU})$.

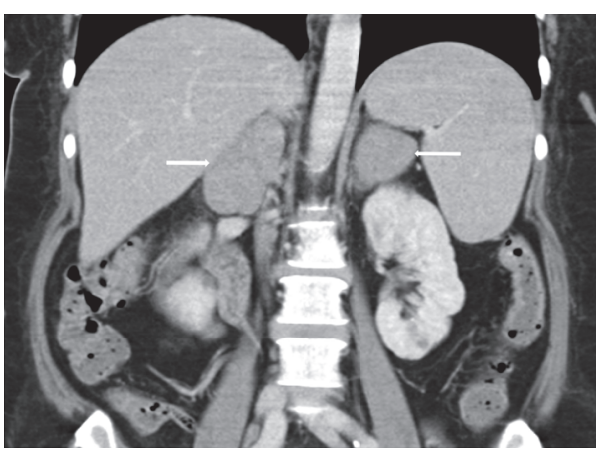

FIgURE 2: At the time of diagnosis. Imaging studies of patient, CT thorax, and abdomen and pelvis show bilateral adrenal masses which are homogenous measuring $3.7 \times 5.4 \times 6.3 \mathrm{~cm}$ on the left $(78.3$ average $\mathrm{HU})$, while the right adrenal gland measures $5.5 \times 2.7 \times$ $5.9 \mathrm{~cm}$ (72.7 average $\mathrm{HU})$.

B-cell origin. MYC was positive in $70 \%$ of tumour cells and Ki-67 proliferation index was 90\%. CD5 was positive; Cyclin D1 and SOX11 were negative, which also excludes mantle cell lymphoma. Bone marrow biopsy did not show any marrow involvement (Figure 6).

The patient was reviewed by a Hematologist, and the decision was made to manage her as for Stage 4 Diffuse Large B-Cell Lymphoma (DLBCL) in view of organ involvement. Her Eastern Cooperative Oncology Group (ECOG) status was zero, and International Prognostic Index (IPI) was one because of raised lactate dehydrogenase. She was treated with six cycles of R-CHOP and four cycles of intrathecal methotrexate chemotherapy.

Remarkably, repeat computer tomography scan after four cycles of R-CHOP chemotherapy showed interval regression of bilateral adrenal masses with nearly normal adrenal glands (Figure 3). The left enlarged supraclavicular and mediastinal nodes remained stable in size.

A Positron Emission Tomography (PET) scan six weeks after completion of both R-CHOP and intrathecal methotrexate revealed no fluorodeoxyglucose (FDG) update in the chest, abdomen, or pelvis and the enlarged left 


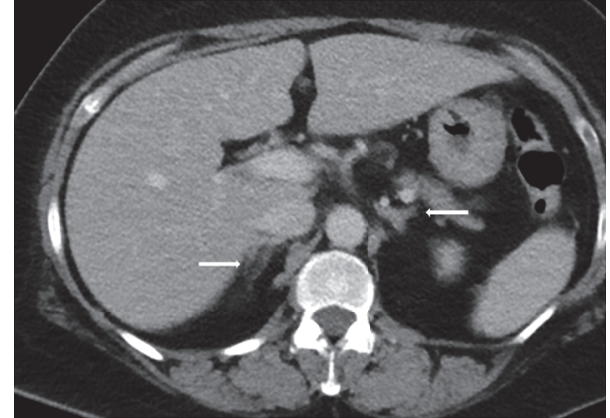

FIGURE 3: At the end of treatment. Imaging studies of the patient after having chemotherapy show interval regression of bilateral adrenal glands with both adrenal glands returning to normal size.

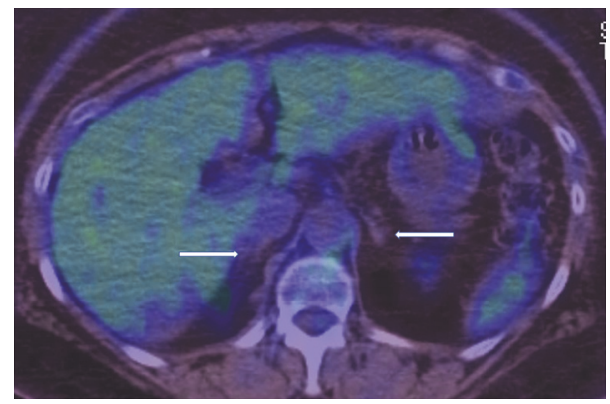

FIgure 4: At the end of treatment. Posttreatment PET-CT scan showing normal sized adrenal glands (white arrows) with no significant FDG activity.

supraclavicular lymph node showed mild-FDG avidity that was smaller in size compared to previous computed tomography scans. This was discussed in a multidisciplinary tumour board, and it was decided to consider this as a reactive lymph node (please see Figures 4 and 5).

She remained in complete remission five months after chemotherapy and have since returned to work. However, repeat Synacthen test showed persistent adrenal insufficiency, and she remained on hydrocortisone replacement therapy. She is being monitored closely by a Hematologist and an Endocrinologist.

\section{Discussion}

Primary adrenal lymphoma is a typically highly aggressive malignancy. As exemplified by our patient, most cases are usually diffuse large B-cell lymphomas and bilateral involvement is frequently observed [3]. Age, tumour size, adrenal insufficiency, lactate dehydrogenase level, and performance status of the patient can significantly influence prognosis $[4,5]$.

Diagnosis can be established with the help of biopsy and histological examination [6]. The European Society of Endocrinology [7] recommends imaging studies and hormonal assessment for bilateral adrenal masses first. This is because there are many differential diagnoses ranging from metastases from a different primary lymphomas or bilateral pheochromocytoma. In addition, there remains a

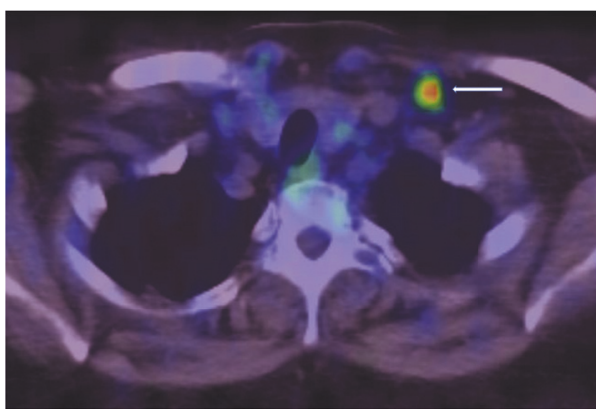

Figure 5: At the end of treatment. Posttreatment PET-CT scan showing a borderline enlarged left supraclavicular lymph node (white arrow) with moderate to intense FDG activity (SUVmax 8.4). In the absence of any significant adenopathy elsewhere in the body, this was deemed to be of reactive nature.

possibility of cooccurrence of different entities, resulting in the necessity of separately characterising each lesion. Biopsy is recommended for hormonally inactive lesions; lesions which cannot be concluded as benign by imaging and histological diagnosis alter the management. Surgical intervention, however, is suggested to be individualised according to various factors including the patient's age, comorbidities, and preferences.

In our case, we elected a percutaneous needle biopsy according to patient preference. It was, therefore, reassuring that posttreatment scans showed resolution of both adrenal masses. In accordance with the works of Ichikawa et al., our patient responded well to a rituximab-containing regimen combined with intrathecal methotrexate, suggesting that this combination is effective against adrenal lymphomas [8].

\section{Conclusion}

Bilateral adrenal lymphoma remains a rare form of nonHodgkin lymphoma and care must be taken in ruling out other causes of bilateral adrenal masses. Subsequent surgical interventions need to be individualised. Although our experience suggests that a rituximab-containing regimen with intrathecal methotrexate is effective, larger studies should ideally be carried out to validate this treatment modality.

\section{Learning Points}

Commonly bilateral adrenal masses are usually due to metastases from malignant tumours arising from lungs, breast, or colon.

Primary DLBCL affecting both adrenals is a rare phenomenon [9].

Diffuse large B-cell lymphoma (DLBCL) is the most common histological subtype.

\section{Conflicts of Interest}

Dr. Veeraraghavan Meyyur Aravamudan, Dr. Phang Kee Fong, Dr. Yang Shiyao Sam, Dr. Pavel Singh, Dr. Gollamudi Satya Pavan Kumar, and Dr. Siok-Bian Ng have no disclosures 


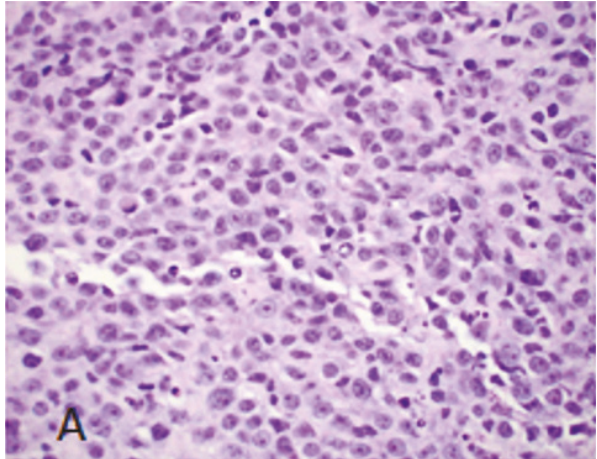

(a)

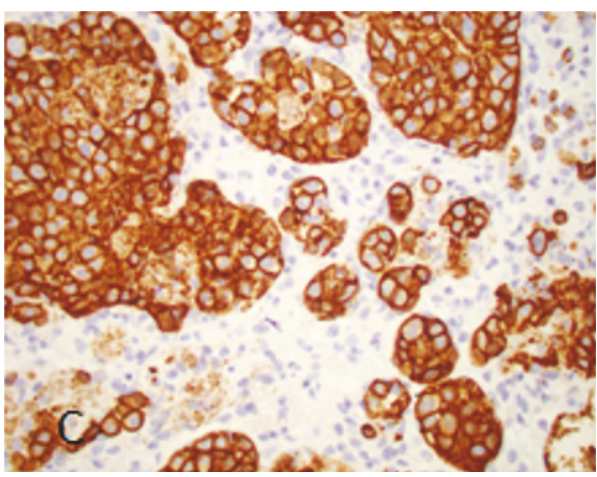

(c)

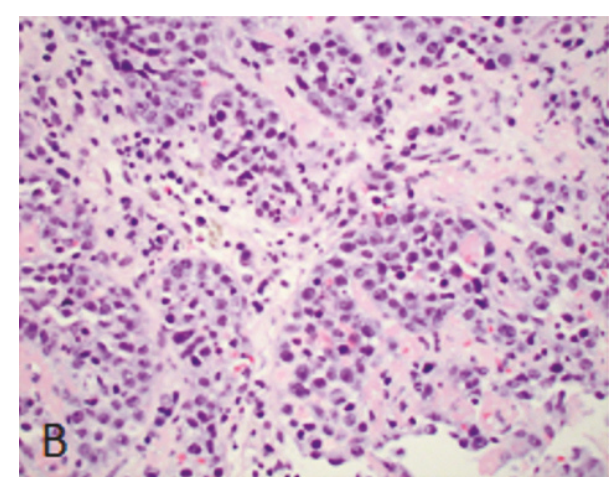

(b)

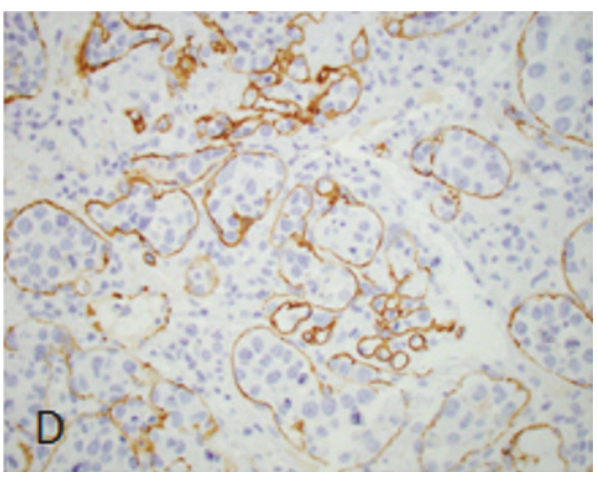

(d)

Figure 6: Histology images. The neoplastic lymphoid cells showed large vesicular nuclei ((a) H\&E, original magnification $\times 600)$ and prominent intravascular growth pattern ((b) original magnification $\times 400)$. They were positive for CD20 ((c) original magnification $\times 600)$. CD34 stain $((d)$ original magnification $\times 400)$ highlighted vascular channels containing neoplastic lymphoid cells, confirming the intravascular growth pattern.

to make and have no conflicts of interest and no funding was received.

\section{Authors' Contributions}

Veeraraghavan Meyyur Aravamudan, Phang Kee Fong, and Yang Shiyao Sam helped in compilation of the text and literature search. Pavel Singh helped in radiological images and literature search. Siok-Bian $\mathrm{Ng}$ helped in editing the manuscript and helped with histopathology images and histopathology report. Gollamudi Satya Pavan Kumar helped in compilation of the text, literature search, and editing the manuscript.

\section{References}

[1] R. Kashyapa, B. R. Mittala, K. Manohara et al., "Extranodal manifestations of lymphoma on [18F]FDG-PET/CT: a pictorial essay," Cancer Imaging, vol. 11, no. 1, pp. 166-174, 2011.

[2] A. Ozimek, J. Diebold, R. Linke, J. Heyn, K. Hallfeldt, and T. Mussack, "Bilateral primary adrenal non-Hodgkin's lymphoma and primary adrenocortical carcinoma-review of the literature preoperative differentiation of adrenal tumors," Endocrine Journal, vol. 55, no. 4, pp. 625-638, 2008.

[3] A. Rashidi and S. I. Fisher, "Primary adrenal lymphoma: a systematic review," Annals of Hematology, vol. 92, no. 12, pp. 1583-1593, 2013.
[4] A. Khurana, P. Kaur, A. K. Chauhan, S. P. Kataria, and N. Bansal, "Primary non hodgkin's lymphoma of left adrenal gland: a rare presentation," Journal of Clinical and Diagnostic Research, vol. 9, no. 4, pp. XD01-XD03, 2015.

[5] A. P. Grigg and J. M. Connors, "Primary adrenal lymphoma," Clinical Lymphoma, vol. 4, no. 3, pp. 154-160, 2003.

[6] B. Laway, M. Lone, S. Aziz, I. Rangreze, and S. Ahmad, "Primary adrenal lymphoma: differential involvement with varying adrenal function," Indian Journal of Endocrinology and Metabolism, vol. 15, no. 3, p. 220, 2011.

[7] M. Fassnacht, W. Arlt, I. Bancos et al., "Management of adrenal incidentalomas: european society of endocrinology clinical practice guideline in collaboration with the european network for the study of adrenal tumors," European Journal of Endocrinology, vol. 175, no. 2, pp. G1-G34, 2016.

[8] S. Ichikawa, N. Fukuhara, A. Inoue et al., "Clinicopathological analysis of primary adrenal diffuse large B-cell lymphoma: effectiveness of rituximab-containing chemotherapy including central nervous system prophylaxis," Experimental Hematology \& Oncology, vol. 2, no. 1, p. 19, 2013.

[9] A. Mozos, H. Ye, W.-Y. Chuang et al., "Most primary adrenal lymphomas are diffuse large B-cell lymphomas with nongerminal center B-cell phenotype, BCL6 gene rearrangement and poor prognosis," Modern Pathology, vol. 22, no. 9, pp. 12101217, 2009. 


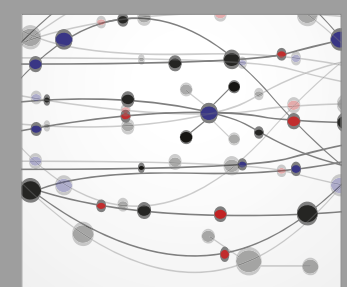

The Scientific World Journal
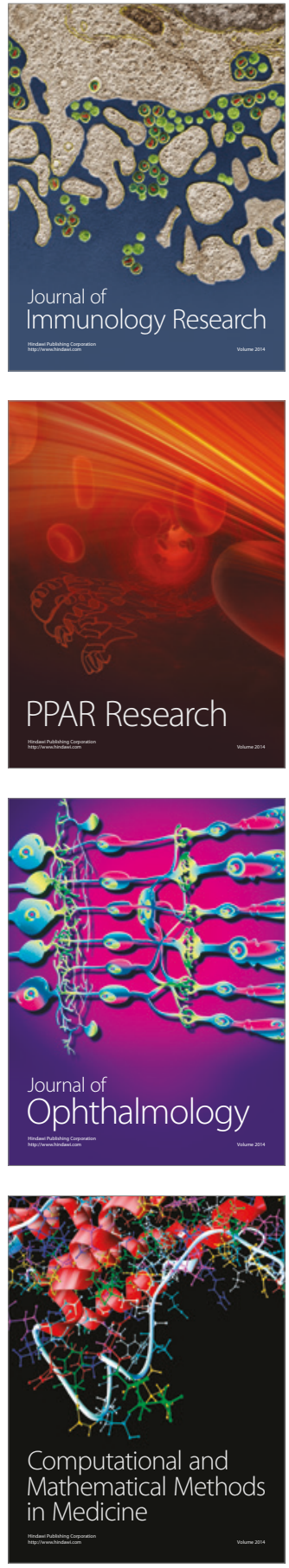

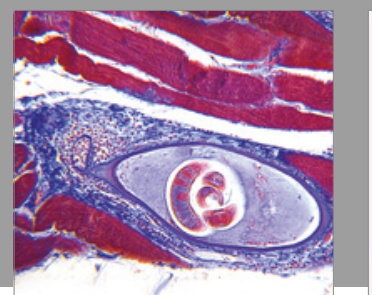

Gastroenterology Research and Practice
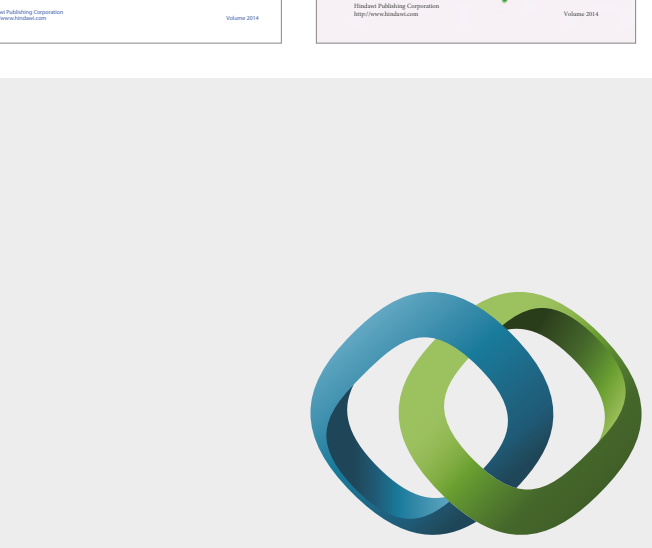

\section{Hindawi}

Submit your manuscripts at

https://www.hindawi.com
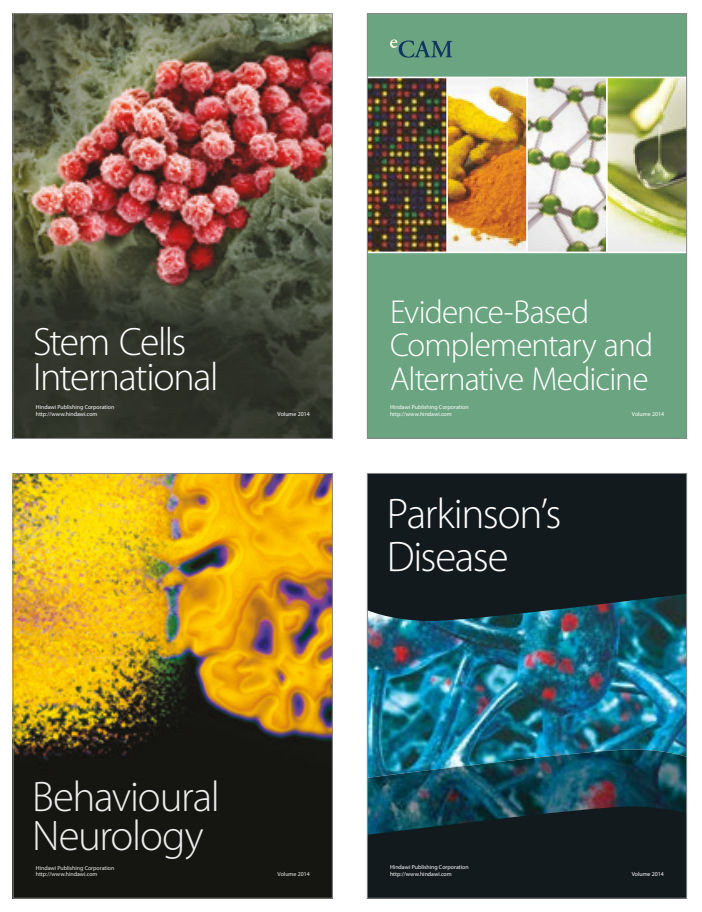
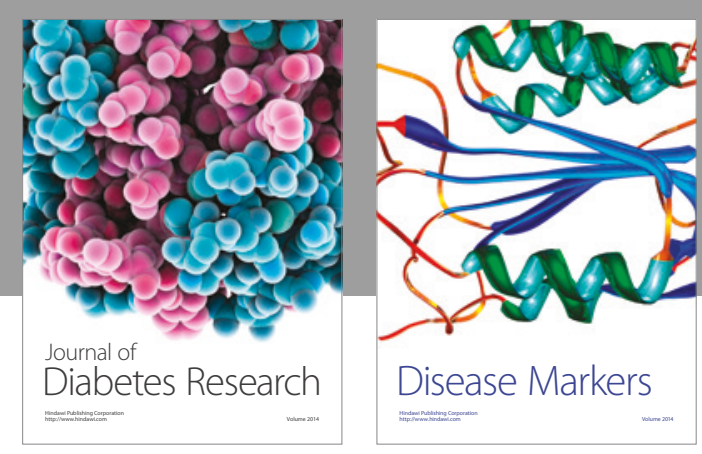

Disease Markers
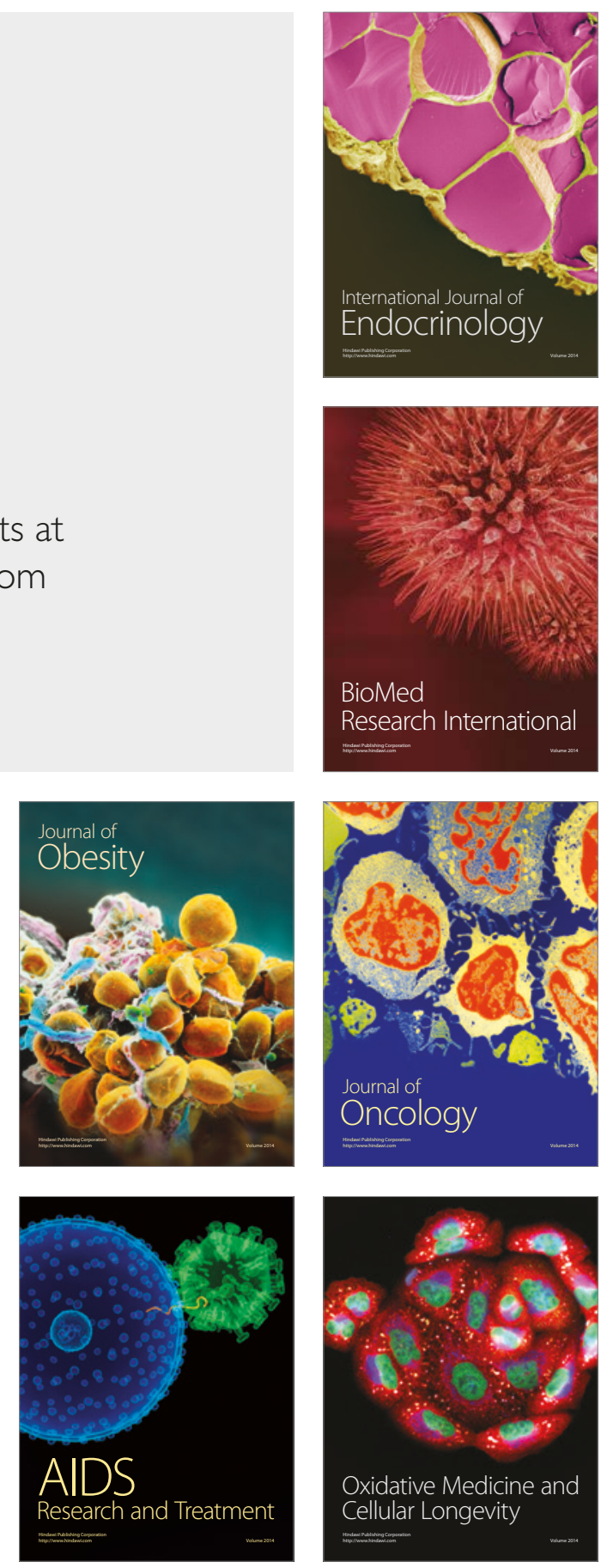